\title{
PRÁTICA SOCIAL DO LETRAMENTO: UMA EXPERIÊNCIA RIZOMÁTICA ACERCA DO CHIMARRÃO
}

\author{
SOCIAL PRACTICE OF LITERACY: A RHIZOMATIC EXPERIENCE ABOUT CHIMARRÃO \\ PRÁCTICA SOCIAL DEL LETRAMENTO: UNA EXPERIENCIA RIZOMÁTICA SOBRE EL \\ CHIMARRÓN
}

\author{
Roberta Stockmanns \\ Universidade Federal do Rio Grande do Sul - UFRGS \\ E-mail: robertastockmanns@gmail.com \\ Miriam Garcia Müller \\ Universidade Federal do Rio Grande do Sul - UFRGS \\ E-mail: miriamgmuller@yahoo.com.br \\ Cláudia Rodrigues de Freitas \\ Universidade Federal do Rio Grande do Sul - UFRGS \\ E-mail: freitascrd@gmail.com
}

\section{RESUMO}

Este artigo tem o objetivo de apresentar uma prática do letramento construída com crianças de sete e oito anos do $2 .^{\circ}$ ano de uma escola pública através de atividades transdisciplinares. Uma proposta de alfabetizar letrando, contribuindo, assim, para a formação de leitores e escritores autônomos e proficientes. Acompanhamos o ponto de partida escolhido pela docente para o ensino da leitura e da escrita, que se transformou em projeto pedagógico e se estendeu ao longo do ano letivo, sendo base para a construção das atividades escolares e efetivando o papel da escola como espaço social.

PALAVRAS-CHAVE: Letramento. Projeto pedagógico. Atividades transdisciplinares. Papel da escola.

\section{ABSTRACT}

This paper aims to present a practice of literacy constructed with children of seven and eight years old of the second year of a public school through transdisciplinary activities. A proposal of alphabetizing with literacy, contributing to the formation of autonomous and proficient readers and writers. We followed the starting point chosen by the teacher for the teaching of reading and writing, which became a pedagogical project and extended throughout the school year, being the basis for the construction of school activities, thus effecting the role of the school as a social space.

KEYWORDS: Literacy. Pedagogical project. Pransdisciplinar activities. Role of the school.

\section{RESUMEN}

Este artículo tiene el objetivo de presentar una práctica del letramento construida con niños de siete y ocho años del 2. ${ }^{\circ}$ año de una escuela pública a través de actividades transdisciplinares. Una propuesta de alfabetizar letrando, contribuyendo así a la formación de lectores y escritores autónomos y proficientes. En el caso de la enseñanza de la lectura y de la escritura, se ha transformado en proyecto pedagógico y se ha extendido a lo largo del año escolar, siendo base para la construcción de las actividades escolares y realizando el papel de la escuela como espacio social.

PALABRAS-CLAVE: Alfabetización. Proyecto pedagógico. Actividades transdisciplinares. Papel de la escuela. 


\section{INTRODUÇÃ̃O}

No final do século $\mathrm{XX}$, em meio às diversas transformações culturais, políticas, tecnológicas, assentam-se as exigências de se exercer uma cidadania ativa dentro de uma sociedade democrática mais justa e igualitária, e, para isso, espera-se que os sujeitos sejam autônomos, participativos e mais conscientes. O papel da educação na contribuição para a formação desses sujeitos se torna imprescindível, pois, às crianças já não basta aprender a ler e a escrever, mas, sim, fazer uso dessas habilidades na sociedade na qual estão inseridas. Dessa forma, teremos indivíduos alfabetizados e em estado de letramento, que, segundo Magda Soares (2004) se refere à imersão do sujeito na cultura escrita, sua participação nas práticas sociais que envolvem a leitura e a escrita.

A sala de aula, sendo um espaço de difusão social e cultural, que deve criar entrelaçamentos entre os sujeitos, os contextos e a linguagem, pode servir de base para práticas do letramento, principalmente ao agregar atividades da vida cotidiana, as quais, normalmente, ficam à parte das experiências escolares. Maria de Lourdes Dionísio (2007) nos convida a pensar o novo letramento: plural, que não envolve somente textos, mas, as práticas na vida das pessoas, as práticas da sociedade na qual o aluno está incluso.

Na cidade de Bom Princípio, localizada no Rio Grande do Sul, estado que tem como um de seus símbolos o chimarrão, em uma escola pública, uma professora, adepta do hábito de tomar chimarrão, propõe à sua turma de alunos do segundo ano: nove meninos e oito meninas, entre sete e oito anos de idade, uma "roda de chimarrão". A proposta foi aceita de forma entusiasmada pelos alunos, pois, trazia algo inusitado: o chimarrão que não fazendo parte do dia a dia na escola, era comum no dia a dia em suas casas. Assunto este que se tornou foco nas primeiras rodas: cada aluno contando como se preparava o mate em suas casas e sobre o que as famílias conversavam ou faziam nestes momentos. A proposta transformou-se em projeto, batizado de "Chimarrão, mais que uma bebida”, estendendo-se por metade do ano letivo e tendo os recursos pedagógicos construídos pelo grupo, tais como portfólio, caderno de campo, apresentação na mostra de iniciação científica da cidade, e,

\footnotetext{
${ }^{1}$ Roda de chimarrão: É o ato de compartilhar entre amigos a cuia de chimarrão. Na roda de chimarrão, uma pessoa é responsável em servir e alcançar o mate aos demais integrantes do grupo que a recebem na ordem em que estão sentados.
} 
também, despertando questionamentos destas duas pesquisadoras do campo da infância e do letramento. Questionamos: Práticas do Letramento estavam sendo desenvolvidas por aquele grupo? Quais eram os recursos pedagógicos utilizados dentro e fora da sala de aula? Como o projeto pedagógico contribuiu para contextualizar o ensino? Esses textos e atividades, trazidos e produzidos pelo grupo, contribuíam para o processo de letramento destes sujeitos?

$\mathrm{Na}$ tentativa de respondermos às interrogações levantadas, observamos e analisamos as práticas de produção de texto desenvolvidas na escola, as interlocuções de linguagem (escrita e falada) estabelecidas entre os alunos e os suportes pedagógicos utilizados pela professora. Para tanto, acompanhamos os participantes do projeto durante a mostra de iniciação científica municipal, bem como realizamos entrevistas com participantes, incluindo a professora. Salientamos, porém, que nossa inserção neste contexto começou do meio... Assim como um rizoma que se conecta de um ponto qualquer a outro, e, como ilustram Deleuze e Guattari (1995), não tem começo nem fim, mas sempre um meio pelo qual ele cresce e transborda.

\section{REFERENCIAL TEÓRICO}

Para buscar respostas aos nossos questionamentos, adotamos os pressupostos da pesquisa de cunho cartográfico como principal aporte teórico-metodológico. Conforme Kastrup e Passos (2013, p. 264), “a pesquisa de campo geralmente coloca o cartógrafo diante de um território que ele não conhece e em relação ao qual pretende fazer avançar o entendimento e as práticas de trabalho". A cartografia, expõe Kastrup (2007), é um método apresentado por Deleuze e Guattari que visa acompanhar um processo e não representar um objeto. Nossa proposta tinha como ponto de partida a observação da subjetividade, porém, também, impulsionávamo-nos na busca de algumas pistas para descrever, discutir e coletivizar nossa experiência (KASTRUP, 2007). A pista que buscávamos era perceber como se deu a construção daquelas aprendizagens em torno do projeto "chimarrão, mais do que uma bebida", e se elas haviam favorecido as relações sociais para serem caracterizadas como práticas sociais do letramento. Dialogamos, portanto, com os estudos de: Kastrup (2007), 
Deleuze e Guattari (1995), Jobim e Souza (1996), Ferreiro (1993), Soares (2004, 2006), Dionísio (2007), Castanheira, Maciel e Martins (2009), Zanellato (2008).

Entendemos, juntamente com os autores acima citados, que as práticas pedagógicas podem ajudar a compreender os padrões culturais, sociais e morais que se relacionam às sociedades e suas heterogeneidades e assim contribuir para uma inserção social consciente destes alunos. O Letramento é uma prática pedagógica, porém, alerta Soares (2006), "muitas vezes ainda é confundido com o conceito de alfabetização". Como vimos, letrar é mais do que alfabetizar, é ensinar a ler e escrever dentro do contexto de vida no qual o aluno está inserido e de acordo com a sociedade na qual ele vive. No projeto em estudo, as crianças em fase de alfabetização foram convocadas a imergir em um processo de ensino-aprendizagem da leitura e da escrita por meio do ensino contextualizado e das práticas sociais do Letramento.

Então, a compreensão de Letramento também como um rizoma torna-se válida, pois, diferentemente de um simples alfabetizar, um sistema arborecente que hierarquiza, o rizomático faz bulbo. "Evolui por hastes e fluxos subterrâneos, ao longo de vales fluviais ou de linhas de estradas de ferro, espalha-se como manchas de óleo". (DELEUZE; GUATTARI, 1995, p. 17).

\section{MÉTODOS E ANÁLISE DOS DADOS}

A pequena cidade de Bom Princípio ${ }^{2}$ se agigantou, aos nossos olhos, nas instalações do centro de convenções onde aconteceu a $4^{\mathrm{a}}$ edição da Mostra de Iniciação Científica Municipal. O lugar era grande e estava cheio; eram pais, professores, alunos, comunidade em geral, circulando entre os estandes, onde os projetos eram expostos por representantes das turmas das escolas do município. Várias apresentações ocorriam ao mesmo tempo, colorindo, pulsando, e, para estas pesquisadoras, dificultando, até, a escolha de onde pausar a atenção, pois naquele ambiente repleto de pequenos pesquisadores, era tudo muito vibrante e estimulante.

\footnotetext{
${ }^{2}$ Possui cerca de 15 mil habitantes, segundo consta no site www.bomprincipio.rs.gov.br/
}

\begin{tabular}{l|l|l|l|l|l} 
C Rev. Triang. & Uberaba, MG & v.11 & n.2 & p. 252-263 & Maio/Ago. 2018
\end{tabular}




\section{Revista Triângulo}

ISSN 2175-1609

O projeto "chimarrão, muito mais que uma bebida" estava representado por três alunos: dois meninos e uma menina, os quais não se deixaram intimidar pelos muitos visitantes, pelas vozes altas e pelas outras apresentações. Vinham à frente do banner e com o olhar buscavam o público, queriam ser vistos! Percebemos que, mesmo as três crianças sendo iniciantes naquele ambiente científico, o contexto agitado não se constituiu em um problema, na verdade aquela situação acabou sendo estímulo para que os pesquisadores procurassem chamar a atenção para si, pois, enquanto explicavam a sua pesquisa, eles buscavam entonação na fala e queriam agradar, satisfazer e manter as expectativas de sua plateia. Eles iniciavam a explanação, contando como uma proposta de roda de chimarrão na sala de aula havia se transformado em um projeto abraçado por eles, pela escola e pela comunidade, para depois se transformar em uma pesquisa e estar sendo apresentado, ali, na mostra. Um projeto, concordamos, rizomático, "voltado para uma experimentação ancorada no real" (DELEUZE; GUATTARI, 1995, p. 20).

Para melhor caracterização ao tema chimarrão, os alunos e a professora trajavam vestimentas típicas de gaúcho: bombacha e vestido de prenda. Um pouco tímida, a menina era a mais preocupada em seguir passo a passo o ensaiado, enquanto nos meninos, podia-se perceber um certo improviso, trazendo elementos vindos à tona naquele momento. Colocamo-nos como expectadoras, enquanto eles explicavam ao público que há alguns meses realizavam pesquisas acerca do chimarrão e tudo havia começado porque tinham descoberto que o hábito de reunir a família para tomar chimarrão estava se perdendo. Assunto bemrecebido pelos visitantes do evento que intrigados e admirados pela proposta escutavam as crianças. Uma primeira pista já se podia observar, aquela certamente era uma prática do Letramento, e, assim como um mapa que não é fechado sobre si mesmo, mas que se constrói, fugia dos padrões categorizados de ensino. O mapa, como explicam Deleuze e Guattari (1995, p. 23), “é aberto, é conectável em todas as suas dimensões, desmontável, reversível, suscetível de receber modificações constantemente. "

Para Jobim e Souza (1996, p. 33), "se por um lado o ser humano é orgânico em sua estrutura, por outro, o seu desenvolvimento, sua marca principal, é a cultura". O chimarrão fazendo parte do dia a dia dos alunos e sendo um dos símbolos do estado em que vivem carrega uma marca cultural. Os relatos dos alunos acerca das nuances desse hábito em suas 
Revista Triângulo

ISSN 2175-1609

casas eram unânimes quanto aos quesitos: presença marcante do aparelho celular nesses momentos de sentar e tomar um chimarrão conversando e o costume dos familiares de tomarem chimarrão sozinhos em momentos diferentes do dia. E, a partir dessa constatação, a professora solicitou um dever de casa inusitado: prepararem um chimarrão para os seus pais e familiares para conversarem juntos, pois este hábito não podia se perder. De acordo com Deleuze e Guattari (1995, p. 18), "as multiplicidades se definem pelo fora: pela linha abstrata, linha de fuga ou de desterritorialização segunda a qual elas mudam de natureza ao se conectarem às outras".

A professora, em entrevista, nos relatou, com muita empolgação, a movimentação que se seguiu à roda de chimarrão envolvendo os pais:

Naquele dia mesmo e nos dias seguintes, inúmeras fotos foram enviadas para o meu
celular, via whats app, pelos pais das crianças com o registro deles e das crianças
tomando chimarrão [ [...] Eu e os alunos nos sentíamos realizados: estávamos
resgatando um importante momento da família e não deixando se perder uma
tradição [...] o assunto tinha potencial [...] e conversando com os alunos, o projeto
foi se estendendo, e, fomos conhecendo mais e mais sobre a história desse costume
... (Professora, idealizadora do projeto "chimarrão, muito mais que uma bebida", em
relato oral).

O aparelho celular passa, então, a ser um aliado, na função registrar e compartilhar, auxiliando na confecção de um portfólio. Segundo Zanellato (2008) o portfólio é um instrumento de registro e situa-se no campo da avaliação progressiva. Para este autor, o uso do portfólio é um caminho para envolver os alunos na identificação e compreensão das próprias aprendizagens.

No portfólio desenvolvido por este grupo, estão as fotos de vários momentos nos quais o chimarrão era o tema disparador de outras atividades, como quando o grupo conheceu a história desta bebida, a lenda da erva-mate, a produção e os benefícios do chimarrão, e, também de quando partilharam estas descobertas em uma grande roda de chimarrão onde os pais foram convidados. O grupo também se aventurou em uma saída de campo até a cidade de Bento Gonçalves - RS, onde está a "Casa da Erva-Mate". Alunos em processo de alfabetização estavam aprendendo por meio de uma prática social, contribuindo para sua aprendizagem no que tange à escrita e à oralidade. Segundo Soares (2006):

Em outras palavras: do ponto de vista individual o aprender a ler e a escrever alfabetizar-se, deixar de ser analfabeto, tornar-se alfabetizado, adquirir a "tecnologia" do ler e escrever e envolver-se nas práticas sociais de leitura e de 


\section{Revista Triângulo}

escrita - tem consequências sobre o indivíduo, e altera seu estado ou condição em aspectos sociais, psíquicos, culturais, políticos, cognitivos e até mesmo econômicos (...) (p. 17-18).

Também, ressaltamos a produção por eles de um caderno de campo. Esta ferramenta serve como um diário, onde é possível registrar histórias, anotar projetos, ideias e objetivos, rabiscar, desenhar, contar sonhos (ZANELLATO, 2008). Nesse caderno de campo encontramos escritos feitos pelos alunos sobre as principais atividades realizadas por eles, por exemplo: as impressões após assistirem a um vídeo sobre a tradição do chimarrão e sobre como ocorre o processo de produção artesanal da erva-mate. Para Deleuze e Guattari (1995), escrever é um processo maquínico e nada tem a ver com significar, mas os seus estratos contêm intensidades e permitem novos agenciamentos, e estes eram facilmente percebidos naqueles textos. $\mathrm{O}$ grupo se mantinha ativo no tema, inclusive, organizou uma exposição de cuias de diferentes tamanhos e formatos e plantou um pé de erva-mate, que está sendo, inclusive, cuidado por eles. Ressalta-se, ainda, a realização de um estudo sobre o porongo, base da cuia onde se toma o chimarrão, e a cabaceira (planta cujo fruto é o porongo), e também, uma palestra sobre o chimarrão, realizada na escola, a convite da professora, dos representantes infantis das tradições do povo gaúcho, o piá farroupilha e a segunda prenda mirim, do Centro de Tradição Gaúcha (CTG) da cidade. Deleuze e Guattari (1995) afirmam que quando são criados agenciamentos se abrem redes de contatos que existem pelo fora e no fora e que estas têm significado.

Ressaltamos que o caderno de campo foi escrito pelas próprias crianças que construíram juntamente com a professora os textos sobre as atividades realizadas. Contrário às práticas convencionais, em que língua escrita fica atrelada à repetição de "fórmulas estereotipadas em que se pratica uma escrita fora do contexto, sem nenhuma função comunicativa com o real" (FERREIRO, 1993, p. 18), o caderno de campo daquela turma buscava preservar as informações vivenciadas. Pois, ao se analisar o caderno, era perceptível que as fases de aquisição da língua escrita dos alunos eram bastante heterogêneas: alguns já utilizam a letra cursiva, outros ainda apresentam letra de caixa (de forma), porém, todos conseguiram formular texto para escrever no caderno de campo. A professora permitiu que aquele registro "formal" contivesse textos com diferentes elementos ortográficos, considerando-os produções relevantes, pois, nas palavras dela: "de tudo o que fizemos ao longo destes meses o que tem mais significado para mim é este caderno". 
Suas escritas constituíam-se de frases completas e textos bastante coesos, algo que nos despertou, pois tal nível de escrita não costuma ser apresentado por crianças desta idade. Como eles conseguiram formular aquelas escritas, sendo "apenas" alunos do $2^{\circ}$ ano? Para Magda Soares (2006), ao permitir que o sujeito interprete, divirta-se, seduza, sistematize, confronte, induza, documente, informe, oriente-se, reivindique e garanta o efetivo uso da linguagem estão lhe sendo oferecidas condições diferenciadas de aprendizagem. Indivíduos autônomos, capazes de construir uma relação com o mundo necessitam de liberdade para poderem criar suas conexões e formarem os entrelaçamentos do seu desenvolvimento. Por isso, a prática da professora se mostra apropriada na perspectiva do Letramento. Castanheira, Maciel e Martins (2009, p. 31) consideram crucial o modo como o professor conduz o seu trabalho "para que a criança construa o conhecimento sobre o objeto escrito e adquira certas habilidades que lhe permitirão o uso efetivo do ler e do escrever em diferentes situações sociais".

Ainda, durante o evento, tivemos acesso a um enfeite de cuia que foi adotado como símbolo do projeto e todas as famílias da turma receberam o mimo. Nele está escrito: "Chima com a família". E, a surpresa, tanto para nós como para a professora, foi a apresentação cantada de uma música gaúcha aprendida durante as aulas para um dos avaliadores. A professora, que não ficava com eles durante as apresentações ao público, apenas estava "por perto" no caso de uma necessidade, informou-nos: "a música não estava prevista no cronograma da apresentação, acho que eles se empolgaram, mas sabe que eu gostei da ideia!”. Quem sabe foi também essa empolgação que os moradores do bairro, onde fica a escola, sentiram, ao verem, segundo os alunos, as "correrias que eram feitas para cima e para baixo, indo com trajes típicos para a escola quando nem era 20 de Setembro" ${ }^{3 "}$ e começaram a se interessar pelo projeto e colaboravam espontaneamente, trazendo cuias, diferentes objetos e histórias para partilhar.

A mostra municipal de iniciação científica teve avaliadores de outros municípios e da região e classificou oito projetos (quatro dos anos iniciais e quatro dos anos finais do Ensino Fundamental) para a Mostratec Júnior, em Novo Hamburgo - RS. O primeiro lugar dos anos iniciais ficou com o projeto "chimarrão, muito mais que uma bebida"!

320 de Setembro: Dia do Gaúcho. Comemoração da Revolução Farroupilha. 


\section{Revista Triângulo}

ISSN 2175-1609

A classificação gerou outro desdobramento: professora e alunos resolveram disseminar a história e a cultura do chimarrão para crianças da mesma idade de outras escolas do município, e assim, motivá-las a também a preparar uma cuia e tomar chimarrão com suas famílias. Por isso, rumaram todos por escolas vizinhas nas semanas que seguiram a classificação. Foram pilchados, sortearam enfeites de cuia e, é claro, levaram cuias e erva para realizarem uma roda de chimarrão. Certamente seria mais cômodo ficar em sala de aula e usar o livro didático para apresentar os signos linguísticos, mas, como diz Ferreiro (1993, p. 35), "por mais bem-intencionados que sejam os manuais e as cartilhas, eles introduzem sempre um elemento de rigidez na aprendizagem". E um trabalho docente efetivo se propõe a organizar as ações, planejar e replanejar as atividades, percebendo o processo de ensinoaprendizagem como capaz de promover a apreensão, mas também determinante para o envolvimento social da leitura e da escrita. Castanheira, Maciel e Martins (2009, p. 57) explicam que "esse movimento implica compartilhar metas - com os alunos, com suas famílias e com a equipe pedagógica”.

Até o término deste artigo, registramos, ainda, outro desdobramento desse projeto: uma viagem para Venâncio Aires - RS, a capital nacional do chimarrão, onde os representantes da turma, seus responsáveis, e a professora conheceram a Escola do Chimarrão. A viagem foi possível graças a um esforço conjunto da prefeitura e dos pais dos alunos. Após a viagem, em conversa com as crianças e com a professora, os relatos eram recheados de pura alegria: Aprendemos muito nesta viagem, foi muito legal, eles tinham mais de 30 cuias
prontas com jeitos diferentes de colocar a erva! (relato de aluno)

Aprendemos sobre os signos do chimarrão. Eu sou de capricórnio e minha mãe é escorpião, eu não sabia disso. Qual é o seu signo? (relato com pergunta de aluno)

O assunto estava tão presente, que, simplesmente, as crianças não paravam de falar sobre tudo o que haviam visto e aprendido, como ressalta Jobim e Souza (1996, p. 22), "ao observarmos as crianças no seu dia a dia, elas brincam, sonham, inventam, produzem e estabelecem relações sociais que, muitas vezes, escapam à lógica do enquadramento cultural normatizado". Estes alunos e essa professora descobriram um entrecruzamento de interesses que fazia sentido para ambos e assim imergiram em um contexto do Letramento significativo. 


\section{CONSIDERAÇÕES FINAIS}

Foi possível constatar que ao logo desses meses o projeto superou as expectativas de todos os envolvidos, se transformando, realmente, em uma pesquisa com perspectivas rizomáticas do Letramento. O envolvimento das famílias e da comunidade se mostrou múltipla, como os fios de uma marionete, "que formam por sua vez uma outra marionete seguindo outras dimensões conectadas às primeiras. Os fios ou hastes que movem as marionetes - chamemo-los a trama”. (DELEUZE; GUATARRI, 1995, p. 17).

Nos registros escritos, foi possível perceber que em muitas oportunidades as crianças partilharam ideias coletadas fora da escola e demonstraram curiosidades não previstas inicialmente, então, professora e grupo incorporavam, dia após dia, mais assuntos acerca do tema ao contexto da sala de aula. Ferreiro (1993, p. 68), ao explicar como se incorporam habilidades e competências no ambiente escolar, diz que "criar as condições para sua aquisição ou ensinar formalmente são duas coisas distintas”. E as práticas pedagógicas que esta professora oportunizou a estas crianças demostram que "as crianças são facilmente alfabetizáveis desde que descubram, através de contextos sociais funcionais que a escrita é um objeto interessante que merece ser conhecido". (FERREIRO, 1993, p. 25).

Os alunos também socializaram depoimentos emocionantes ocorridos durante a roda de chimarrão com suas famílias e estavam sempre ansiosos em relatar as histórias aprendidas. Era possível perceber que a cooperação dos pais dos alunos começou tímida, mas adquiriu grandes proporções, o que contribuiu para estreitar os laços e motivar ainda mais as crianças, que teciam uma rede de afeto entre elas, suas famílias e a escola. Dionísio (2007) tece inferências sobre a aprendizagem, a construção do conhecimento é mediada por textos, sejam eles escritos com linguagem verbal ou sejam textos que integram múltiplos sistemas, é compreensível que haja nos estudos do Letramento uma preocupação com as práticas pedagógicas. E explica o que seria o Novo Letramento:

Os Novos Estudos do Letramento têm se orientado em dois sentidos. Um que não visa imediatamente à escola, à aprendizagem e à educação. $\mathrm{O}$ outro sentido que tem sempre subjacente a ideia de criar condições para que a escola e a educação respondam, de forma produtiva, eficiente, eficaz, àquilo que são, na verdade, as práticas de letramento dos indivíduos na sociedade, (p. 214). 
Observou-se que o tema do projeto foi base para grande parte das aulas que passaram a ser transdisciplinares, os estudantes, cativados pelo assunto, participaram de forma integral de todas as ações propostas e construíram aprendizagens significativas que contribuíram para o processo do Letramento deles. Os registros (orais, escritos, fotográficos, gráficos, etc) demonstram que as práticas sociais do Letramento realizadas por estes alunos e por esta professora mostram que o calor da cuia passando de mão em mão foi fio condutor de bonitas histórias que certamente não serão esquecidas e constituirão nas crianças e na professora memórias positivas e alegres. Com esse estudo o chimarrão passou a ser, para este grupo de alunos e suas famílias, para esta professora e para esta escola e comunidade, muito mais que uma bebida, pois ele uniu pessoas e fortaleceu laços e assim como um rizoma se ramificou de diferentes formas e sentidos.

\section{REFERÊNCIAS}

CASTANHEIRA, M.; MACIEL, F.; MARTINS, R. Alfabetização e Letramento na sala de aula. (organizadoras). 2. ed., Belo Horizonte, MG: Autêntica, 2009.

DELEUZE, G.; GUATTARI, F. Mil Platôs. São Paulo, SP: Editora 34, 1995.

DIONÍSIO, Maria de Lourdes. Entrevista. In: PERSPECTIVA, Florianópolis, v. 25, n. 1, 209-224, Jan./Jun. 2007.

FERREIRO, Emilia. Com todas as letras. 3. ed., tradução Maria Zilda da Cunha Lopes; retradução e cotejo de texto Sandra Trabucco Valenzuela. São Paulo, SP: Cortez, 1993.

JOBIM E SOUZA, Solange. Infância e Linguagem: Bakhtin, Vygotsky e Benjamin. 3. ed., Campinas, SP: Papirus, 1996.

KASTRUP, V. O funcionamento da atenção no trabalho cartográfico. Psicologia \& Sociedade, p. 15-22, Jan./Abr., 2007. 
KASTRUP, V.; PASSOS, E. Cartografar é traçar um plano comum. Fractal, Rev. Psicol., v. 25 - n. 2, p. 263-280, Maio/Ago. 2013. Disponível em: http://www.scielo.br/pdf/fractal/v25n2/04.pdf Acesso em: 05/02/2018.

SOARES, M. Letramento e alfabetização: as muitas facetas. Revista Brasileira de Educação, n.25, jan.-abr./2004.

SOARES, M. Letramento: um tema em três gêneros. Belo Horizonte, Autêntica, 2006.

ZANELLATO, José R. Portfolio como instrumento de avaliação no ensino de graduação de artes visuais. Dissertação de mestrado. PUC - Campinas, 2008. 